\title{
The Cost Effectiveness of Lubiprostone in Chronic Idiopathic Constipation
}

\author{
Becky Pennington ${ }^{1} \cdot$ Emily-Ruth Marriott $^{1} \cdot$ Peter Lichtlen $^{2} \cdot$ Ayesha Akbar $^{3,4}$. \\ Anthony J. Hatswell ${ }^{1,5}$
}

Published online: 4 January 2018

(C) The Author(s) 2018. This article is an open access publication

\begin{abstract}
Objective The objective of this study was to evaluate the cost effectiveness of lubiprostone, prucalopride, placebo and immediate referral to secondary care in chronic idiopathic constipation (CIC) in an economic model that was used by the UK National Institute for Health and Care Excellence (NICE) in developing guidance.

Methods We developed a cohort state-transition model to reflect the treatment pathway in CIC from the UK NHS and personal social services perspective. Time on treatment was determined by a treatment continuation rule using data from an indirect comparison and survival curves fitted to long-term data. Quality of life was defined by whether CIC was resolved or unresolved, using published values. Costs were determined by drug acquisition costs, invasive procedures and healthcare resource use (associated with resolved or unresolved CIC), using published UK sources. Deterministic and probabilistic sensitivity analyses were conducted.

Results Over a 10-year time horizon, lubiprostone was more costly and more effective than placebo and
\end{abstract}

\section{Electronic supplementary material The online version of this} article (https://doi.org/10.1007/s41669-017-0065-9) contains supplementary material, which is available to authorized users.

Anthony J. Hatswell

ahatswell@deltahat.co.uk

1 BresMed Health Solutions LTD, North Church House, 84 Queen Street, Sheffield S1 2DW, UK

2 Sucampo AG, Zug, Switzerland

3 St Mark's Hospital, Harrow, UK

4 Imperial College London, London, UK

5 University College London, London, UK immediate referral to secondary care, with incremental cost-effectiveness ratios (ICERs) of $£ 58,979$ and $£ 21,152$. Lubiprostone dominated prucalopride in the base case and with a time horizon of 1 year. The main sensitivity for the comparison against placebo was the assumptions around placebo cost and efficacy. The main sensitivity for the comparison against prucalopride was the endpoint used in the indirect comparison.

Conclusion Lubiprostone may be cost effective compared with prucalopride or immediate referral but not compared with placebo in the base case. The implementation of the guidance issued by NICE should increase quality of life for patients with CIC and provide a further treatment option.

\section{Key Points for Decision Makers}

There is large uncertainty in the clinical pathway for chronic idiopathic constipation.

Multiple indirect comparisons are possible between treatments using different endpoints.

Lubiprostone appears to be a cost-effective option at UK list price compared with prucalopride and immediate referral.

\section{Introduction}

Chronic idiopathic constipation (CIC) is a common disorder characterized as constipation over an extended time period with no known cause. The most widely accepted 
definition of CIC uses the Rome IV diagnostic criteria [1], which requires that patients fulfil certain symptom criteria relating to their bowel habit, including the relative frequency of defecations [2]. It is distinct from irritable bowel syndrome in that abdominal pain is not the key feature. CIC has a severe impact on the health and wellbeing of patients, with the size of the effect comparable to that of musculoskeletal diseases, diabetes, heart disease and depression $[3,4]$.

As disease onset is slow [5] and diagnosis is often delayed because patients self-medicate, the exact prevalence of CIC is unknown [6]. One estimate suggests that approximately 570,000 adult patients in England and Wales have general practitioner (GP)-diagnosed constipation [6]. The diagnosis involves taking a detailed history, excluding secondary causes, and investigations as appropriate. Depending on the patient's symptoms and the physician, investigation may include blood tests, colonoscopy, transit studies and anorectal physiology.

Lubiprostone (Amitiza ${ }^{\circledR}$, Takeda UK Ltd) is a locally acting chloride channel-2 activator. The safety and efficacy of lubiprostone in CIC was studied in three phase III randomized controlled trials (RCTs) $(n=603)$ [7-9]. These studies demonstrated that lubiprostone significantly increased spontaneous bowel movements (SBMs) and other clinically relevant endpoints compared with placebo. Evidence of sustained efficacy is also available from four long-term open-label studies [9-12].

In the UK, the National Institute for Health and Care Excellence (NICE) seeks to review the clinical and costeffectiveness evidence of new medicines, aiming to maximize the health (defined in terms of quality-adjusted lifeyears [QALYs]) of the population within a fixed healthcare budget. In August 2013, NICE elected to assess lubiprostone as a treatment for CIC in a single technology appraisal. The scope of the appraisal was to compare lubiprostone with bulk-forming, osmotic and stimulant laxatives and prucalopride in a population of adults with CIC, when response to diet and other non-pharmacological measures are inappropriate [13]. The cost-effectiveness results considered in developing the final appraisal determination are reported elsewhere [14]. In this study, we describe the economic model and inputs, update the costs to year 2016 values and report results of a less conservative analysis (using most likely estimates for parameters according to expert validation) in which we considered a longer time horizon, such that patients were in comparable states at the end of the model, and an additional comparator to reflect the clinical pathway in the UK.

\section{Methods}

\subsection{Model Structure}

There is no consensus pathway for the management of CIC, so we conducted advisory boards with clinical experts. The five experts involved in the process were clinicians currently working in the UK NHS in a variety of settings, including one GP, three secondary care consultant gastroenterologists and one gastrointestinal medicine expert. Their views were collected in a questionnaire prior to meeting and then through discussion to reach unanimous agreement. Their unanimous view was that lubiprostone would be used when at least two laxatives had failed, because many inexpensive laxatives would have been used before this. The objective of treatment at this stage is to treat patient's symptoms and avoid unnecessary referrals to investigations and invasive procedures.

We constructed a cohort state-transition model in Microsoft ${ }^{\circledR}$ Excel. State-transition models are appropriate where a disease can be categorized into mutually exclusive and collectively exhaustive states and where any individuals in the same health state have the same quality of life and the same healthcare resource use. The health states were chosen to reflect the treatment pathway and whether a person had resolved or unresolved CIC. The health states in the model were as follows:

- 'treatment', during which patients receive lubiprostone, placebo or prucalopride,

- 'investigations/invasive procedures', in which all patients visit a gastroenterologist, 95\% have a colonoscopy, and $61 \%$ undergo invasive procedures (of which $98.9 \%$ are biofeedback, $1.0 \%$ are sacral neuromodulation, $0.1 \%$ are stoma surgery) [15],

- 'resolved', which patients enter if the invasive procedures are curative $(95 \%$ probability for sacral neuromodulation and stoma surgery, $62 \%$ for biofeedback) [16], and

- 'unresolved', which patients enter if they have been treated with lubiprostone or prucalopride and invasive procedures are either not received or not curative.

Figure 1 shows the structure of the economic model. We used a cycle length of 2 weeks - the duration of the initial trial period of lubiprostone.

The perspective of the model was NHS and personal social services. Costs and QALYs were discounted annually at 3.5\% [17]. The NICE reference case for economic evaluation stipulates that the time horizon for estimating clinical and cost effectiveness should be sufficiently long to reflect any differences in costs or outcomes between the technologies being compared. For a comparison against 


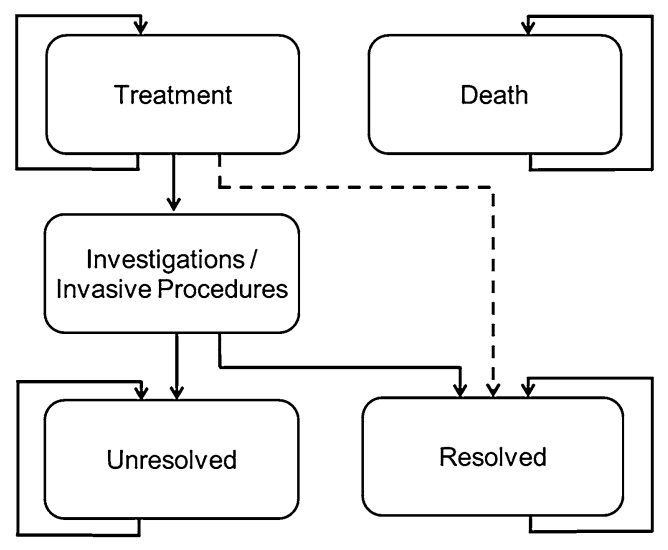

Fig. 1 Economic model structure. The dashed line indicates transition is considered in the scenario analysis only and not in the base case

another active drug (prucalopride), a short time horizon is sufficient. However, for comparison with immediate referral, a longer time horizon is required to capture all relevant differences and ensure patients are in comparable health states at the end of the model period. We therefore present results for a 1-year time horizon (as considered by NICE) and for a 10 -year time horizon.

\subsection{Comparators}

We considered prucalopride, placebo and immediate referral to secondary care as comparators. Prucalopride is arguably the most relevant comparator, as it is licensed and recommended in the same indication [18]. However, questions remain over what the most appropriate comparator is where prucalopride is not used. In the NICE appraisal, placebo was considered as a comparator and was assumed to be representative of standard laxative treatment (which patients received alongside placebo in the trial). Since referrals to investigations and invasive procedures are being considered in this indication, we included immediate referral to secondary care as an additional comparator.

\subsection{Clinical Inputs}

On the advice of clinicians, the economic model incorporated a treatment continuation rule that determined whether or not a patient had adequately responded and should continue treatment beyond the initial period.

The initial period for lubiprostone and placebo is 2 weeks, based on the UK summary of product characteristics for lubiprostone [19]. In order to continue treatment after the initial trial period, patients must have had three or more SBMs with no use of rescue medication during week 2 ; for placebo, this was $53.5 \%$ of patients based on a meta- analysis of the RCTs. The relative risk of response at week 2 for lubiprostone compared with placebo was 1.30 [20].

The initial trial period for prucalopride is 4 weeks before response is assessed [21, 22]. When response at week 4 is defined as having three or more SBMs with no use of rescue medication during week 4 , a total of $50.0 \%$ of patients receiving placebo responded and the relative risk of response at week 4 for lubiprostone compared with placebo was 1.38. The probability of response at week 4 for prucalopride was calculated by multiplying the placebo response by the relative risk for lubiprostone versus placebo and dividing by the relative risk for lubiprostone versus prucalopride.

The relative risk for lubiprostone versus prucalopride was calculated from indirect comparisons. The RCTs for lubiprostone and prucalopride had different primary endpoints, and the prucalopride trial did not include the definition of response used in the lubiprostone analysis. Therefore, the relative effectiveness of lubiprostone versus prucalopride was estimated from other outcomes. Several outcomes were common to both lubiprostone and prucalopride trials, which permitted indirect comparisons to be performed for seven different measures (Table 1). The indirect comparisons used the Bucher approach [23], and methods are described elsewhere [20, 23]. The base case used the 'change in SBM from baseline' (the primary endpoint of the lubiprostone studies), which showed numerical superiority for lubiprostone over prucalopride without reaching statistical significance. The relative effectiveness of prucalopride compared with lubiprostone was applied in the model to the definition of response.

To incorporate treatment discontinuation beyond the stopping rule at week 2 or 4 , parametric curves were fitted to discontinuation data beyond week 2 from the long-term open-label lubiprostone studies combined with long-term US prescription data [12]. The rate of discontinuation after implementation of the treatment continuation rule was assumed to be the same for prucalopride as for lubiprostone because the reasons for discontinuation would be similar. The best-fitting curve, according to visual inspection, Akaike information criterion and Bayesian inference criterion, was the log-logistic, with scale parameter 4.26 and shape parameter 0.24 . For placebo, the base-case scenario considered that patients discontinued treatment using the same data, and a scenario analysis considered that placebo had no lasting effect after the initial 2-week period, with all patients then discontinuing to be moved to investigative treatment.

Patients who responded to treatment remained on treatment until they discontinued. After non-response (at week 2 for lubiprostone or week 4 for prucalopride) or discontinuation, patients moved immediately into the 'investigations/invasive procedures' health state, where they 
Table 1 Relative risks derived from indirect comparisons of lubiprostone versus prucalopride

\begin{tabular}{lll}
\hline Outcome & $\begin{array}{l}\text { Lubiprostone vs. prucalopride } \\
\text { RR (95\% CI) }\end{array}$ & Favours \\
\hline Change in SBM from baseline & $1.12(0.77-1.64)$ & Lubiprostone \\
Percentage of patients achieving an average increase in SBM of $\geq 1$ over weeks 1-4 & $1.04(0.84-1.28)$ & Prucalopride \\
SBMs rated as 'normal' & $0.73(0.63-0.85)$ & Prucalopride* \\
SBMs rated as 'hard' or 'very hard' & $0.78(0.60-1.01)$ & Lubiprostone \\
SBMs with no straining & $1.27(0.79-2.03)$ & Lubiprostone \\
SBMs with severe/very severe straining & $0.67(0.48-0.92)$ & Lubiprostone* \\
Mean change in SCBM from baseline over weeks 1-4 & $2.60(0.59-4.61)$ & Lubiprostone \\
Assume same efficacy & 1.00 & Neither \\
\hline
\end{tabular}

$C I$ confidence interval, $R R$ relative risk, $S B M$ spontaneous bowel movement, $S C B M$ spontaneous complete bowel movement $* p<0.05$

remained for one cycle. A proportion of patients moved from 'investigations/invasive procedures' into 'resolved' and the remainder into 'unresolved', where they remained until the end of the model time horizon.

All-cause mortality was included in the model, using age- and sex-specific mortality data from life tables for England and Wales [24]. In the base case, it was assumed that CIC affected only quality of life and not survival. There is some evidence that constipation may be linked to increased mortality [25-28], so a scenario was considered using a hazard ratio for mortality of 1.19 for unresolved versus resolved CIC [29].

\subsection{Health-Related Quality of Life}

A large ( $n=1200)$ study in CIC enrolling patients in the USA and Canada reported EuroQol Five-Dimension (EQ5D) utility scores at baseline $(0.83)$ and for responders (0.90) and non-responders (0.86) [30]. The model assumed that the utility in the initial trial period for placebo, lubiprostone and prucalopride was an average of responder and non-responder utilities, weighted for the proportion of responders for each treatment. Beyond the initial period, the utility value for patients who continued on treatment was that of a responder, since they had, by definition, responded to treatment. Patients undergoing invasive procedures were non-responders to treatment and so had the utility value for a non-responder. Following invasive procedures, patients who were cured had the utility value for a responder. Those whose condition remained unresolved were assumed to have a poorer quality of life than those at an earlier stage in the pathway and were not assumed to receive active treatment, so had the utility value from baseline (Table 2).

\subsection{Costs}

All patients in the economic model receiving lubiprostone, placebo or prucalopride incurred the cost of the initial treatment period before response was assessed. Lubiprostone (dosed $24 \mu \mathrm{g}$ twice daily) was available in a 2 -week starter pack (28 tablets), costing £29.68 [31]. Beyond this initial period, patients who met the treatment continuation rule continued to receive lubiprostone in a larger pack of 56 tablets (4 weeks), costing $£ 53.48$ [31]. Prucalopride (dosed $2 \mathrm{mg}$ once daily in adults and $1 \mathrm{mg}$ once daily in the elderly), is available only in 4-week (28 tablets) packs costing $£ 59.52$ (2 mg) and $£ 38.69$ (1 mg) [31]. In the pivotal lubiprostone trials, $11.3 \%$ of patients were aged $>65$ years [7-9]. To create an unbiased comparison, this percentage of patients aged $>65$ years from the lubiprostone trials was used, which led to a weighted cost of $£ 57.17$ for prucalopride. All patients receiving prucalopride incurred this cost before response was assessed (at 4 weeks).

In the NICE submission, placebo was assumed to have no cost. However, since placebo is assumed to be representative of further laxative treatment, placebo was costed in our revised analysis as the simple average of all standard laxative treatments (including bulk-forming laxatives, stimulant laxatives and osmotic laxatives), as per Table 72 of the evidence review group (ERG) report, with drug costs taken from the British National Formulary (BNF) [31, 32]. In the clinical trials for lubiprostone, patients could be given rescue medication if they had no SBM for 3 consecutive days. The proportions of patients receiving lubiprostone or placebo who required a bisacodyl (Dulco$\operatorname{lax}^{\circledR}$ ) suppository as rescue medication were 30 and $39 \%$ in weeks $1-2$ and 15 and $20 \%$ in weeks 3-4, respectively (see Table 1 in the Electronic Supplementary Material [ESM]). The proportion of prucalopride-treated patients requiring 
Table 2 Health state costs and utilities

\begin{tabular}{|c|c|c|c|c|c|c|c|}
\hline \multicolumn{3}{|l|}{ Costs } & \multicolumn{3}{|l|}{ Number of units per 2-week cycle } & \multirow{2}{*}{$\begin{array}{l}\text { Investigations/ } \\
\text { invasive } \\
\text { procedures }\end{array}$} & \multirow[t]{2}{*}{ Sources } \\
\hline Item & $\begin{array}{l}\text { Unit } \\
\text { cost } \\
(\mathfrak{f})\end{array}$ & Source & On treatment & Resolved & Unresolved & & \\
\hline GP home visit & $100^{\mathrm{a}}$ & \multirow[t]{3}{*}{ PSSRU 2016 [36] } & 0.0161 & 0.0092 & 0.0345 & 0.0345 & \multirow{6}{*}{$\begin{array}{r}\text { Guest et al. } \\
\text { [34] } 2008\end{array}$} \\
\hline $\begin{array}{l}\text { GP telephone } \\
\text { consultations }\end{array}$ & 14 & & 0.0387 & 0.0176 & 0.0552 & 0.0552 & \\
\hline GP clinic visit & 31 & & 0.4734 & 0.1549 & 0.5044 & 0.5044 & \\
\hline Laboratory test & 3 & \multirow{5}{*}{$\begin{array}{l}\text { NHS reference costs } \\
\text { 2015-16 [35] }\end{array}$} & 0.0448 & 0.0222 & 0.0606 & 0.0606 & \\
\hline $\begin{array}{l}\text { Accident and } \\
\text { emergency visit }\end{array}$ & 115 & & 0.0015 & 0.0008 & 0.0023 & 0.0023 & \\
\hline $\begin{array}{l}\text { Hospital outpatient } \\
\text { appointment } \\
\text { (follow-up) }\end{array}$ & 132 & & 0.0134 & 0.0092 & 0.0123 & 0.0123 & \\
\hline $\begin{array}{l}\text { Hospital outpatient } \\
\text { appointment (first } \\
\text { attendance) }\end{array}$ & 165 & & & & & 1 & $\begin{array}{l}\text { Expert } \\
\text { opinion }\end{array}$ \\
\hline Colonoscopy & 371 & & & & & 0.95 & \\
\hline Stoma surgery & 1310 & \multirow{4}{*}{$\begin{array}{l}\text { PRU NICE costing } \\
\text { template, inflated to } \\
2015-16 \text { [43] }\end{array}$} & & & & 0.001 & \multirow{4}{*}{$\begin{array}{l}\text { PRU NICE } \\
\text { costing } \\
\text { template } \\
{[43]}\end{array}$} \\
\hline $\begin{array}{l}\text { Sacral } \\
\text { neuromodulation }\end{array}$ & 9660 & & & & & 0.01 & \\
\hline Biofeedback & $792^{\mathrm{b}}$ & & & & & 0.989 & \\
\hline Total cost & & & $£ 18.97$ & $£ 7.39$ & $£ 22.00$ & $£ 1056.74$ & \\
\hline Utility value & \multicolumn{2}{|r|}{ Huang et al. [30] 2012} & $\begin{array}{l}\text { Before stopping rule: PL } 0.88 \text {; } \\
\text { LUB 0.89; PRU 0.88. After } \\
\text { stopping rule: } 0.90\end{array}$ & 0.90 & 0.83 & 0.86 & $\begin{array}{l}\text { Huang et al. } \\
\text { [30] } 2012\end{array}$ \\
\hline
\end{tabular}

GP general practitioner, $L U B$ lubiprostone, NICE UK National Institute for Health and Care Excellence, $P L$ placebo, $P R U$ prucalopride, $P S S R U$ Personal Social Services Research Unit

${ }^{a}$ Assumed half hour GP time

${ }^{\mathrm{b}} \mathrm{Six}$ outpatient follow-up appointments

rescue medication was assumed to be the same as that for those receiving lubiprostone. A 12-pack of 10-mg Dulcolax ${ }^{\circledR}$ suppositories costs $£ 3.53$ according to the BNF [31].

The mean ingestion rate of lubiprostone for patients on treatment in the clinical trials was $83 \%$ (standard error $1.5 \%$ ) [33], so reduced dosing was considered for lubiprostone in the base case. For the scenarios focusing on comparison with prucalopride, full dosing of both lubiprostone and prucalopride was assumed as data on reduced dosing for prucalopride were not available. All treatments may be prescribed either in primary care by a GP or in secondary care during an outpatient appointment with a gastroenterologist [32]. The base case in the economic model assumed it was equally likely (50:50 split) that these were initiated by a GP or a gastroenterologist. Assessment of the treatment continuation rule was assumed in the base case to be performed through a telephone consultation, $80 \%$ of which were assumed to be with a nurse and the remainder with a GP.
Medical resource use was defined by whether a patient was receiving active treatment and whether their constipation was resolved or unresolved. Another study in constipation reported the frequency of accident and emergency visits, hospital outpatient visits, laboratory tests and GP contact for patients receiving Macrogol 4000 and lactulose over 3 months [34]. Resource use was reported separately for monotherapy and combination therapy, for patients who remained on initial therapy, switched therapy or discontinued therapy. It was assumed that patients on initial therapy represented those on initial therapy in our model, those who switched therapy represented those whose CIC was unresolved, and those who discontinued therapy were resolved, averaging Macrogol 4000 and lactulose. The costs of resources were taken from NHS Reference Costs 2015-16 [35] and Personal Social Services Research Unit (PSSRU) Unit Costs of Health and Social Care 2016 [36]. Costs for referral to investigations and invasive procedures were taken from the NICE assessment of prucalopride, 
updated to year 2016 values [15]. Table 2 shows the costs and utilities.

\subsection{Model Validation}

Before the model was submitted to NICE, a senior health economist with no involvement in the project verified and critiqued the model according to a checklist to determine whether the calculations were appropriate and correct. Subsequently, as part of the NICE process, the model was verified and critiqued by an independent academic centre and discussed by an expert committee to validate the structure, assumptions and inputs [37].

\subsection{Analysis}

The base-case analysis presented here makes three changes to the scenario considered by NICE. First, the cost of placebo treatment was included to reflect the costs of laxative treatment, and immediate referral was added as a comparator. Second, the costs were updated by using 2016 sources. Third, the time horizon was extended to 10 years to ensure patients receiving immediate referral were in health states comparable to those receiving lubiprostone, prucalopride or placebo at the end of the model.

Deterministic and probabilistic analyses were performed for the base-case analysis. Probabilistic sensitivity analysis was conducted by simultaneously sampling each parameter from its probability distribution and calculating the total costs and QALYs for each arm. This was done 1000 times (as the result stabilised by this point), and the mean total costs and QALYs for each arm from the 1000 simulations were used to calculate incremental results. Distributions for cost, resource use and utilities are shown in Table 1 in the ESM. Response to placebo was sampled from a beta distribution with alpha equal to the number of responders and beta the number of non-responders. Relative risks for lubiprostone versus placebo and for prucalopride versus lubiprostone were sampled from log-Normal distributions. Discontinuation parameters were sampled from a multivariate Normal distribution. For the base case, the probability that each treatment is the most cost effective at a threshold of $£ 20,000$ per QALY was calculated (the lower end of the suggested NICE 'threshold' for determining a cost-effective medicine) [17]. This analysis was performed to capture parameter uncertainty.

One-way deterministic sensitivity analysis was conducted by setting each parameter in turn to the lower and then upper bound of its $95 \%$ confidence interval. This analysis was performed to explore the key drivers of the cost-effectiveness results.

Scenario analyses were performed for the six other indirect comparisons possible between lubiprostone and prucalopride (in addition to testing the assumption of equal efficacy). A scenario where CIC influenced mortality was considered, as was a scenario where placebo had no lasting effect beyond 2 weeks. These scenarios explored the structural uncertainty associated with model assumptions.

\section{Results}

\subsection{Patient Flow}

After the initial treatment period, 69.3 and $61.5 \%$ of patients were eligible to continue treatment with lubiprostone or prucalopride, respectively. After 1 year, $8.1 \%$ of patients remained on lubiprostone, $8.1 \%$ on prucalopride, and $6.0 \%$ on placebo. After 10 years, all patients had discontinued lubiprostone, prucalopride or placebo. Figure 2 shows the proportion of patients in each health state over the time horizon for each treatment.

\subsection{Base-Case Results}

Table 3 presents the results of the deterministic analysis considered by NICE and the stepwise changes to meet the (deterministic and probabilistic) base case for this analysis. The base-case deterministic results show that immediate referral is both the least costly and the least effective option. Placebo (representing standard care) is more expensive and generates more QALYs, with a resulting incremental cost-effectiveness ratio (ICER) of £9909/ QALY. Lubiprostone is more expensive and more effective than placebo and immediate referral as patients spend longer on treatment, generating both costs and QALYs. Lubiprostone has an ICER of $£ 58,979$ compared with placebo or $£ 21,152$ compared with immediate referral. This means that lubiprostone is not cost effective compared with placebo but is cost effective compared with immediate referral at a threshold of $£ 30,000 / \mathrm{Q} A L Y$. Prucalopride is more costly than lubiprostone, primarily because the drug costs are higher, but less effective than lubiprostone based on the results of the indirect comparison and patients spending less time on treatment due to this lower efficacy. Prucalopride is therefore dominated by lubiprostone.

\subsection{Sensitivity Analyses}

\subsubsection{Probabilistic Sensitivity Analyses}

Table 3 contains probabilistic base-case results, and Fig. 3 shows a cost-effectiveness acceptability curve for the four options. At a willingness to pay below approximately $£ 10,000$ per QALY, the most cost-effective option is immediate referral. As willingness to pay increases, 
Fig. 2 Patient flow
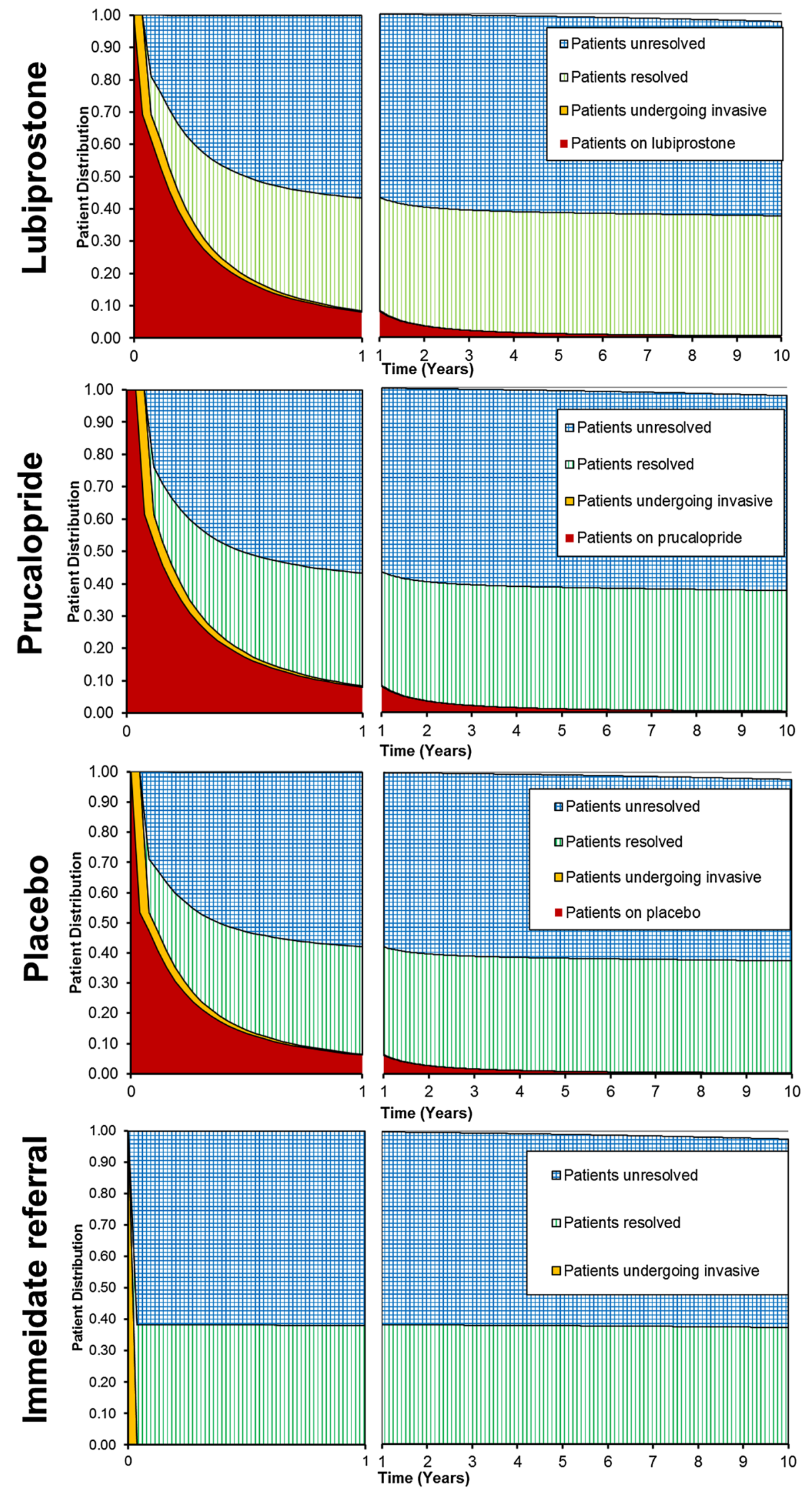
Table 3 Base-case economic model results

\begin{tabular}{|c|c|c|c|c|c|c|c|c|}
\hline \multirow[t]{2}{*}{ Variables } & \multicolumn{3}{|l|}{ Total } & \multicolumn{3}{|c|}{ Incremental } & \multirow[t]{2}{*}{$\operatorname{ICER}(£)$} & \multirow[t]{2}{*}{ ICER vs. baseline $(\mathfrak{f})$} \\
\hline & Costs $(£)$ & LYs & QALYs & Costs $(£)$ & LYs & QALYs & & \\
\hline \multicolumn{9}{|l|}{ NICE analysis } \\
\hline Placebo & 1506 & 0.9958 & 0.8619 & & & & & \\
\hline Lubiprostone & 1672 & 0.9958 & 0.8645 & 165 & 0.0000 & 0.0026 & 64,464 & 64,464 \\
\hline Prucalopride & 1713 & 0.9958 & 0.8643 & 41 & 0.0000 & -0.0002 & Dominated & 87,085 \\
\hline \multicolumn{9}{|c|}{ NICE analysis, with placebo cost, and immediate referral added } \\
\hline Immediate referral & 1455 & 0.9958 & 0.8532 & & & & & \\
\hline Placebo & 1522 & 0.9958 & 0.8619 & 67 & 0.0000 & 0.009 & 7756 & 7756 \\
\hline Lubiprostone & 1672 & 0.9958 & 0.8645 & 149 & 0.0000 & 0.003 & 58,256 & 19,279 \\
\hline Prucalopride & 1713 & 0.9958 & 0.8643 & 41 & 0.0000 & 0.000 & Dominated & 23,358 \\
\hline \multicolumn{9}{|c|}{ NICE analysis, with placebo cost, and immediate referral added, year 2016 values } \\
\hline Immediate referral & 1527 & 0.9958 & 0.8532 & & & & & \\
\hline Placebo & 1573 & 0.9958 & 0.8619 & 46 & 0.00 & 0.009 & 5287 & 5287 \\
\hline Lubiprostone & 1717 & 0.9958 & 0.8645 & 145 & 0.00 & 0.003 & 56,549 & 16,984 \\
\hline Prucalopride & 1759 & 0.9958 & 0.8643 & 42 & 0.00 & 0.000 & Dominated & 21,084 \\
\hline \multicolumn{9}{|c|}{ Base-case: deterministic analysis } \\
\hline \multicolumn{9}{|c|}{ NICE analysis, with placebo cost, immediate referral added, and 10-year time horizon } \\
\hline Immediate referral & 4755 & 8.5324 & 8.4812 & & & & & \\
\hline Placebo & 4889 & 8.5324 & 8.4947 & 134 & 0.00 & 0.014 & 9909 & 9909 \\
\hline Lubiprostone & 5126 & 8.5324 & 8.4987 & 237 & 0.00 & 0.004 & 58,979 & 21,152 \\
\hline Prucalopride & 5195 & 8.5324 & 8.4985 & 69 & 0.00 & 0.000 & Dominated & 25,324 \\
\hline \multicolumn{9}{|c|}{ Base case: probabilistic analysis } \\
\hline Immediate referral & 4744 & 8.5308 & 8.4808 & & & & & \\
\hline Placebo & 4879 & 8.5308 & 8.4945 & 135 & 0.0000 & 0.0136 & 9869 & 21,129 \\
\hline Lubiprostone & 5118 & 8.5308 & 8.4986 & 240 & 0.0000 & 0.0041 & 58,795 & 58,795 \\
\hline Prucalopride & 5192 & 8.5308 & 8.4986 & 74 & 0.0000 & 0.0001 & 777,053 & 75,178 \\
\hline
\end{tabular}

ICER incremental cost-effectiveness ratio, LYs life-years, NICE UK National Institute for Health and Care Excellence, QALYs quality-adjusted life-years

lubiprostone and prucalopride become more attractive options. At around £40,000-50,000/QALY, prucalopride has a higher probability of being cost effective than lubiprostone as, in some simulations, prucalopride is more effective than lubiprostone and has a lower ICER compared with placebo than does lubiprostone. Conversely, in the scenarios where lubiprostone is more effective than prucalopride, the ICERs for both prucalopride and lubiprostone versus placebo are above $£ 50,000$, so placebo is the most cost-effective treatment. At around $£ 60,000$ / QALY, lubiprostone has a higher probability of being cost effective than placebo. As the willingness to pay increases, both lubiprostone and prucalopride increase in probability of being the optimum treatment; however, both rise in tandem because of the uncertainty in the relative efficacy.

\subsubsection{Deterministic Sensitivity Analyses}

Figure 4 shows the tornado diagrams for the comparison between lubiprostone and placebo and between lubiprostone and prucalopride. These two comparisons are presented as they represent the decision problem considered by NICE. The comparison between lubiprostone and placebo used base-case settings. The net benefit of lubiprostone compared with placebo using a threshold of $£ 20,000$ (incremental QALYs $\times £ 20,000$ threshold - incremental costs) was always negative, showing that, even at the upper and lower bounds of each parameter, lubiprostone was not cost effective compared with placebo.

The biggest drivers were the response rate for placebo, proportion of patients cured by biofeedback and the utility value for responders. When more placebo-treated patients responded, the response rate for lubiprostone also increased and the costs and QALYs for both arms increased-but the 
Fig. 3 Cost-effectiveness acceptability curve

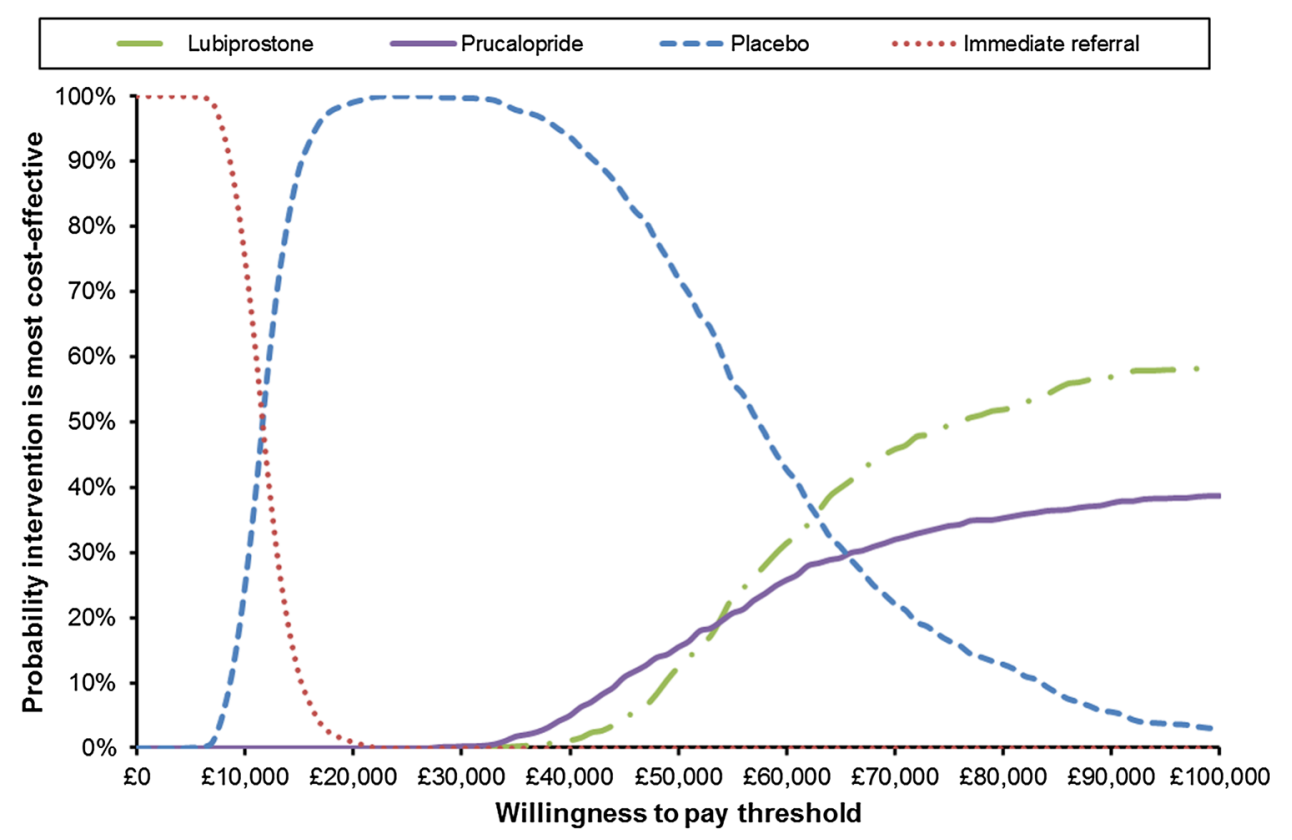

relative increase in costs was greater for lubiprostone, so the ICER increased. When the effectiveness of biofeedback increased, biofeedback became more cost effective-since more placebo-treated patients underwent biofeedback, the cost effectiveness of placebo increased. When the utility value for responders increased, the quality-of-life benefit of lubiprostone increased, leading to an increase in the net benefit of lubiprostone.

The comparison between lubiprostone and prucalopride used base-case settings but an ingestion rate of $100 \%$ for lubiprostone. The net benefit of lubiprostone using a threshold of $£ 20,000$ was always positive-showing that, even at the upper and lower bounds of each parameter, lubiprostone was cost effective compared with prucalopride. The biggest drivers were the proportion having a GP visit (rather than a consultation with a gastroenterologist) to prescribe each drug, and the relative efficacy of lubiprostone and prucalopride. It is unsurprising that one drug would become more cost effective than the other if it could be prescribed in primary rather than secondary care whereas the other could not. The impact of relative efficacy was explored in scenario analyses.

\subsubsection{Scenario Analyses}

We conducted deterministic and probabilistic scenario analyses varying the relative effectiveness of lubiprostone and prucalopride using different outcomes from the indirect comparison. In all cases, the incremental net benefit at $£ 20,000 / \mathrm{Q} A L Y$ was positive for lubiprostone. Even where prucalopride was more effective than lubiprostone, it was not cost effective compared with lubiprostone as the additional cost resulting from the higher treatment cost and longer duration was not sufficiently outweighed by the QALYs gained at standard willingness-to-pay thresholds.

In an analysis using a different source of utilities [34], the difference between responder and non-responder was greater, so the ICER for lubiprostone versus placebo decreased to $£ 49,802 / \mathrm{QALY}$ (as lubiprostone provided more time in a responder health state).

In a scenario including increased mortality for unresolved CIC, the absolute life-years and QALYs for each treatment decreased. However, since there was a mortality benefit to remaining on treatment, the incremental QALYs for placebo versus immediate referral and lubiprostone versus placebo increased slightly, so both ICERs decreased ( 9599 for placebo vs. immediate referral, and $£ 20,592$ for lubiprostone vs. placebo). Prucalopride continued to be dominated by lubiprostone.

We considered an extreme scenario where the effect of placebo treatment was limited to 2 weeks. In this case, the ICER for placebo versus immediate referral increased to $£ 77,959 /$ QALY and the ICER for lubiprostone versus placebo decreased to $£ 17,926 /$ QALY because the benefit of placebo was much reduced. However, the long-term efficacy of placebo is currently unknown.

\section{Discussion}

This analysis showed that, at a willingness to pay of $£ 20,000-30,000 /$ QALY, placebo was the most cost-effective treatment. Lubiprostone was cost effective compared with immediate referral and dominated prucalopride but 
Fig. 4 Tornado diagram using 95\% confidence interval of parameters: a lubiprostone vs. placebo and b lubiprostone vs. prucalopride. GP general practitioner, ITT intention to treat, $Q A L Y S$ quality-adjusted life-years, $S B M$ spontaneous bowel movement
A

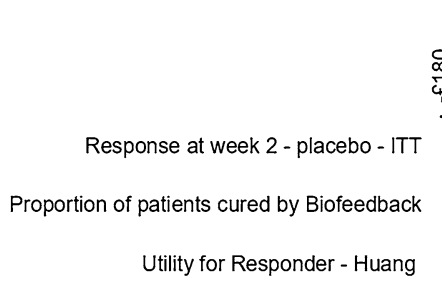

Net benefit at $£ 20,000 /$ QALY

\begin{tabular}{|c|c|c|c|c|c|c|c|c|}
\hline$\frac{b}{10}$ & $\frac{R}{\frac{R}{4}}$ & $\sum_{4}^{\infty}$ & $\frac{8}{C_{1+1}}$ & 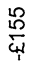 & $\frac{8}{6}$ & 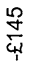 & $\sum_{i+1}^{O}$ & $\frac{m}{m_{W}}$ \\
\hline
\end{tabular}

Proportion of patients who undergo invasive procedures

Utility for Baseline - Huang

Lubiprostone ingestion rate

Number of GP visits in clinic - initial therapy

Response at week 2 - lubiprostone v placebo - ITT

Number of GP visits in clinic - unresolved

Cost - GP Visit
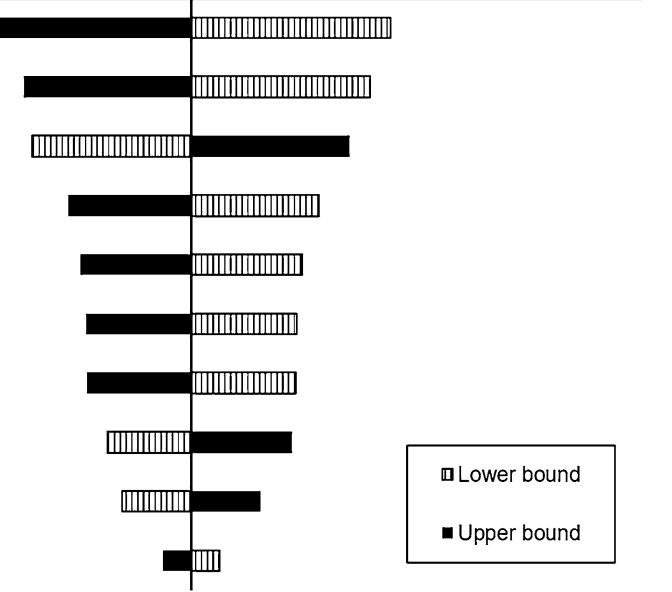

B

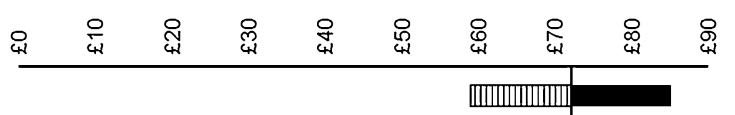

Proportion of patients who undergo invasive procedures

Lubiprostone v Prucalopride - Mean change in SBM from baseline at week 1-4

Proportion over 65

Utility for Responder - Huang

Proportion of patients cured by Biofeedback
Net benefit at $£ 20,000 /$ QALY

qLower bound

- Upper bound
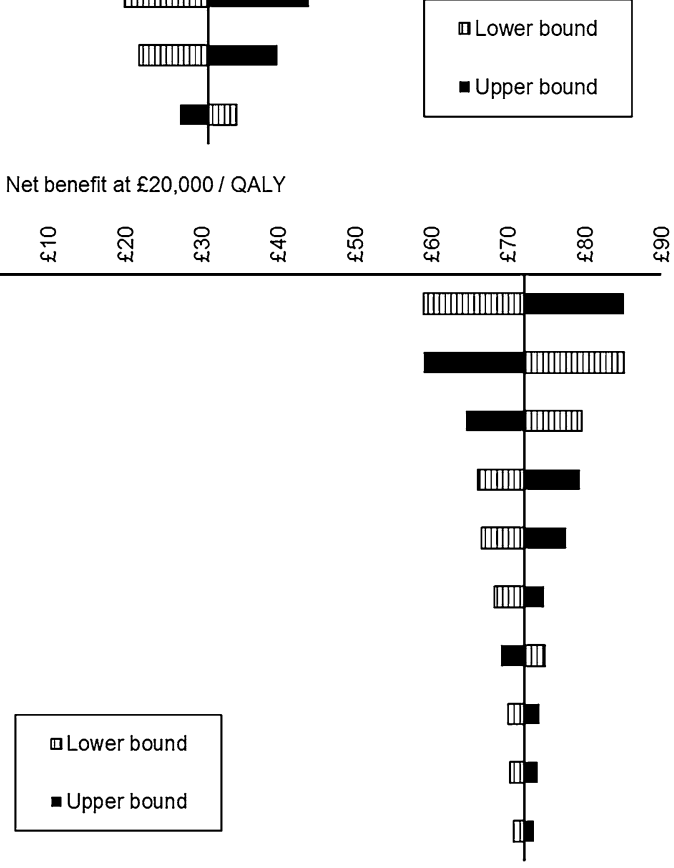

- Upper bound was not cost effective compared with placebo in the base case. NICE recommended lubiprostone on the grounds that it was at least as effective as prucalopride and has a slightly lower acquisition cost but noted that evidence is insufficient to demonstrate it is cost effective compared with placebo.

The major source of uncertainty in determining whether lubiprostone represents value for money therefore is in understanding the treatment pathway without lubiprostone. This appears to be driven by the lack of clear guidelines for the treatment of patients despite the condition being relatively common. If lubiprostone is positioned as a treatment for people for whom at least two previous laxatives have failed and in whom invasive procedures are being considered, assuming patients would receive standard laxatives (represented by placebo) may not be appropriate. This would indicate the most appropriate comparison is versus immediate referral. For these patients, lubiprostone avoids or delays referrals to investigations and invasive procedures, partially offsetting the costs of the drug, with patient quality of life improved (as shown by the QALY gain).

The comparison against prucalopride demonstrated that lubiprostone was cost effective in all scenarios. Although it was not possible to conduct analyses using the same endpoint that was used to model response to lubiprostone and placebo, it was possible to conduct indirect comparisons on seven different endpoints across a range of efficacy outcomes. Whilst lubiprostone appeared more effective in most, this rarely reached statistical significance, leading to uncertainty as to whether prucalopride or lubiprostone is the more effective treatment. In scenario analysis where prucalopride was assumed to be more effective than lubiprostone, whilst prucalopride generated more QALYs, lubiprostone remained cost effective because of lower costs. A recent network meta-analysis in CIC included lubiprostone and prucalopride, with change in SBM as the 
outcome. Although the numerical results of this network meta-analysis were not identical to our analysis (due to differences in methods and included studies), the study found the two drugs to be equally effective, similar to the conclusions of our analyses [38]. When both are equally effective, lubiprostone is cost saving because of lower drug costs. However, it should be noted that these results may not apply in a subgroup of elderly patients, where the dose and hence cost of prucalopride is lower. We were unable to estimate the relative cost effectiveness of lubiprostone and prucalopride in this specific population as we did not have data for the effectiveness of both treatments in this subgroup alone. It would not be appropriate to assume the same effectiveness as the base case because effectiveness may differ in the elderly population, particularly when considering a reduced dose of prucalopride.

This is the first study to consider the cost effectiveness of lubiprostone in the treatment of CIC in the UK, though an economic evaluation was performed for prucalopride in this indication as part of a previous NICE appraisal [18]. The results of the previous economic model showed prucalopride to have an ICER of $£ 16,000$ compared with placebo, which is lower than the ICER for this comparison from our model $(£ 79,670)$. This difference appears to be mainly due to different model structures and time horizons. We consider our model to be more accurate, as it reflects the treatment pathway after failure of the initial treatment and over a much longer time horizon, after which patients will be in the same health states, and thus consequences from treatment were appropriately costed. A targeted literature search identified four other economic evaluations in chronic constipation. One study looked at the cost effectiveness of prucalopride in the Netherlands; this economic evaluation used the same model structure, comparators and assumptions as the aforementioned previous NICE appraisal but used costs relevant to Dutch payers and considered a longer time horizon [39]. Huang et al. [40] developed a decision tree model comparing linaclotide with lubiprostone in the USA. Response to therapy was defined as (1) having one of the best two satisfaction answers of a 5-point global treatment satisfaction scale at week 4 or (2) having a weekly SBM frequency $\geq 4$ at week 4. The time horizon used was 4 weeks, and results showed both treatments resulted in equal QALYs, so only a cost comparison was made. Linaclotide is not licensed in the UK so was not included in our model. Taylor et al. [41] and Guest et al. [34] compared Macrogol 3350 and Macrogol 4000 to lactulose, respectively. Both studies used a decision tree model with timelines of 3 and 6 months.

In the appraisal of lubiprostone, the NICE appraisal committee concluded the model structure was valid for the decision problem, on account of it considering treatment stopping rules, discontinuation and referral to secondary care. The committee reviewed the data sources and assumptions and found them to be appropriate [32]. This process, together with the critique of the model by an independent economist, and verification of the model calculations by an independent review group, addresses some of the best practices recommended for model validation [42]. An important part of validation that we were unable to address involves comparing predicted results with those observed in longitudinal studies. We used the long-term published lubiprostone studies as data sources in the model, so could not then validate against them. We could not identify any additional long-term follow-up studies conducted since we developed the model. This is not surprising, given there was no requirement from reimbursement or licensing agencies to collect additional data. Routine collection of long-term data would facilitate validation of future modelling studies in functional bowel disorders.

Some limitations to the model are linked to the data available. Most notable here are the assumptions around the extrapolation of efficacy and discontinuation data beyond the relatively short clinical trials ( 48 weeks for the open-label studies [12]), despite the chronic nature of the condition. Despite the limitations of the data, sensitivity analyses demonstrated that the results of the model were robust to different data sources and assumptions, with lubiprostone being cost effective compared with prucalopride in all scenarios, and not cost effective compared with placebo except in extreme scenarios.

In conclusion, lubiprostone has been shown to be a costeffective treatment compared with prucalopride or immediate referral in CIC but not compared with placebo. The implementation of the guidance issued by NICE [32] should increase the quality of life for patients with CIC for whom previous treatments have failed, should provide a further treatment option, and may save NHS resources depending on the comparator displaced in practice-either in avoiding unnecessary tests or, more likely, in displacing prucalopride, which has a higher acquisition cost. As the number of health technology appraisals in this area increases, we hope this leads to the provision of further evidence-based guidelines in the area and clarification on the most appropriate treatment pathway.

Acknowledgements The authors would like to acknowledge the input of the advisory board members, Hannah Sophia, Taryn LoschBeridon, and Martin Wang of Sucampo, Alison Saunders of Bioexcel, and both the NICE committee and evidence review group, who provided insightful comments on how to improve the economic model.

Author Contributions The model was constructed by BP, ERM and AJH; clinical input was provided by AA and PL. Further interpretation was provided by BP and AJH. All authors reviewed and approved the final manuscript. 


\section{Compliance with Ethical Standards}

Conflict of interest BP, ERM and AJH are or were employees of BresMed, which was reimbursed by Sucampo for preparing this manuscript and has provided services to Shire (the manufacturer of prucalopride). PL is an employee of Sucampo AG, the manufacturers of lubiprostone (and-at the time the study was conducted-the marketing authorisation holder). AA has received funding from Sucampo and Shire.

Data availability statement Meta-analyses and input data are in the public domain and already available. The economic model may be requested from the authors.

Open Access This article is distributed under the terms of the Creative Commons Attribution-NonCommercial 4.0 International License (http://creativecommons.org/licenses/by-nc/4.0/), which permits any noncommercial use, distribution, and reproduction in any medium, provided you give appropriate credit to the original author(s) and the source, provide a link to the Creative Commons license, and indicate if changes were made.

\section{References}

1. Drossman D, Hasler W. Rome IV-functional GI disorders: disorders of gut-brain interaction. Gastroenterology. 2016;150:1257-61.

2. Longstreth GF, Thompson WG, Chey WD, Houghton LA, Mearin F, Spiller RC. Functional bowel disorders. Gastroenterology. 2006;130(5):1480-91. https://doi.org/10.1053/j.gastro. 2005.11.061.

3. Belsey J, Greenfield S, Candy D, Geraint M. Systematic review: impact of constipation on quality of life in adults and children. Aliment Pharmacol Ther. 2010;31(9):938-49. https://doi.org/10. 1111/j.1365-2036.2010.04273.x.

4. Wald A, Scarpignato C, Kamm MA, Mueller-Lissner S, Helfrich I, Schuijt C, et al. The burden of constipation on quality of life: results of a multinational survey. Aliment Pharmacol Ther. 2007;26(2):227-36. https://doi.org/10.1111/j.1365-2036.2007. 03376.x.

5. Johanson JF, Kralstein J. Chronic constipation: a survey of the patient perspective. Aliment Pharmacol Ther. 2007;25(5):599-608. https://doi.org/10.1111/j.1365-2036.2006. 03238.x.

6. Shafe AC, Lee S, Dalrymple JS, Whorwell PJ. The LUCK study: laxative Usage in patients with GP-diagnosed Constipation in the UK, within the general population and in pregnancy. An epidemiological study using the General Practice Research Database (GPRD). Therapeut Adv Gastroenterol. 2011;4(6):343-63. https://doi.org/10.1177/1756283x11417483.

7. Johanson JF, Morton D, Geenen J, Ueno R. Multicenter, 4-week, double-blind, randomized, placebo-controlled trial of lubiprostone, a locally-acting type- 2 chloride channel activator, in patients with chronic constipation. Am J Gastroenterol. 2008;103(1):170-7. https://doi.org/10.1111/j.1572-0241.2007.01524.x.

8. Barish CF, Drossman D, Johanson JF, Ueno R. Efficacy and safety of lubiprostone in patients with chronic constipation. Dig Dis Sci. 2010;55(4):1090-7. https://doi.org/10.1007/s10620-0091068-x.

9. Fukudo S, Hongo M, Kaneko H, Takano M, Ueno R. Lubiprostone increases spontaneous bowel movement frequency and quality of life in patients with chronic idiopathic constipation.
Clin Gastroenterol Hepatol. 2015;13(2):294-301. https://doi.org/ 10.1016/j.cgh.2014.08.026 (e5).

10. Johanson JF, Gargano MA, Holland PC. Multicenter open-label study of oral lubiprostone for the treatment of chronic constipation [Abstract 903]. Am J Gastroenterol. 2005;100(Suppl 9):S331.

11. Ueno R, Wahle A, Panas R, Joswick TR, Rivera E. Evaluation of safety and efficacy in a twelve month study of lubiprostone for the treatment of chronic idiopathic constipation [Abstract 1269]. Am J Gastroenterol. 2006;101(Suppl 2):S491.

12. Lembo AJ, Johanson JF, Parkman HP, Rao SS, Miner PB Jr, Ueno R. Long-term safety and effectiveness of lubiprostone, a chloride channel (ClC-2) activator, in patients with chronic idiopathic constipation. Dig Dis Sci. 2011;56(9):2639-45. https:// doi.org/10.1007/s10620-011-1801-0.

13. National Institute for Health and Care Excellence (NICE). TA318: Single Technology Appraisal (STA). Lubiprostone for treating chronic idiopathic constipation. Matrix of consultees and commentators: Appendix B. 2013. https://www.nice.org.uk/ guidance/TA318/documents/constipation-chronic-idiopathiclubiprostone-final-scope2. Accessed 05 May 2017.

14. National institute for Health and Care Excellence (NICE). Final Appraisal Determination: Lubiprostone for treating chronic idiopathic constipation. 2014. https://www.nice.org.uk/guidance/ ta318/documents/constipation-chronic-idiopathic-lubiprostonefinal-appraisal-determination-document2. Accessed 17 Aug 2017.

15. NICE. TA211: Prucalopride for the treatment of chronic constipation in women. Costing template. 2011. https://www.nice.org. uk/guidance/ta211/resources. Accessed 26 Sept 2014.

16. Wang J, Luo MH, Qi QH, Dong ZL. Prospective study of biofeedback retraining in patients with chronic idiopathic functional constipation. WJG. 2003;9(9):2109-13.

17. National Institute for Health and Care Excellence (NICE). Guide to the methods of technology appraisal 2013. 2013. https://www. nice.org.uk/process/pmg9/chapter/foreword. Accessed 05 May 2017.

18. NICE. TA211: Prucalopride for the treatment of chronic constipation in women. 2010. http://guidance.nice.org.uk/TA211/ Guidance/pdf/English. Accessed 4 Oct 2013.

19. electronic Medicines Compendium (eMC). AMITIZA 24 microgram soft capsules. 2016. https://www.medicines.org.uk/ emc/medicine/28268. Accessed 17 Aug 2017.

20. Hatswell A, Griffiths A, Lichtlen P, Losch-Beridon T, Pennington B. Which metric to choose for indirect comparison of treatments when multiple comparisons are feasible: lubiprostone vs. prucalopride in chronic constipation. ISPOR. Amsterdam: The Netherlands; 2014.

21. electronic Medicines Compendium (eMC). Resolor $1 \mathrm{mg}$ filmcoated tablets. 2015. https://www.medicines.org.uk/EMC/ medicine/23204/SPC/Resolor+1mg+film-coated+tablets/.

Accessed 17 Aug 2017.

22. electronic Medicines Compendium (eMC). Resolor $2 \mathrm{mg}$ filmcoated tablets. 2015. https://www.medicines.org.uk/emc/ medicine/23206. Accessed 17 Aug 2017.

23. Bucher H, Guyatt G, Griffith L, Walter S. The results of direct and indirect treatment comparisons in meta-analysis of randomized controlled trials. J Clin Epidemiol. 1997;50(6):683-91.

24. Office for National Statistics (ONS). England and Wales, Interim Life Tables, 2009-2011. 2013. http://www.ons.gov.uk.

25. Salmoirago-Blotcher E, Crawford S, Jackson E, Ockene J, Ockene I. Constipation and risk of cardiovascular disease among postmenopausal women. Am J Med. 2011;124(8):714-23. https:// doi.org/10.1016/j.amjmed.2011.03.026.

26. Watanabe T, Nakaya N, Kurashima K, Kuriyama S, Tsubono Y, Tsuji I. Constipation, laxative use and risk of colorectal cancer: 
the Miyagi Cohort Study. Eur J Cancer. 2004;40(14):2109-15. https://doi.org/10.1016/j.ejca.2004.06.014.

27. Koloski NA, Jones M, Wai R, Gill RS, Byles J, Talley NJ. Impact of persistent constipation on health-related quality of life and mortality in older community-dwelling women. Am J Gastroenterol. 2013;108(7):1152-8. https://doi.org/10.1038/ajg.2013.137.

28. Roberts MC, Millikan RC, Galanko JA, Martin C, Sandler RS. Constipation, laxative use, and colon cancer in a North Carolina population. Am J Gastroenterol. 2003;98(4):857-64. https://doi. org/10.1111/j.1572-0241.2003.07386.x.

29. Chang JY, Locke GR 3rd, McNally MA, Halder SL, Schleck CD, Zinsmeister AR, et al. Impact of functional gastrointestinal disorders on survival in the community. Am J Gastroenterol. 2010;105(4):822-32. https://doi.org/10.1038/ajg.2010.40.

30. Huang H, Taylor D, Carson R, Sarocco R, Menzin J. Impact of treatment response on quality of life and work productivity among patients with irritable bowel syndrome with constipation or chronic constipation: pooled results from Phase III clinical trails [Abstract number 1449]. Am J Gastroenterol. 2012;107:S577.

31. National Institute for Health and Care Excellence (NICE). British National Formulary 2017. https://bnf.nice.org.uk/. Accessed 20 Oct 2017.

32. NICE. TA318: Constipation (chronic idiopathic)—lubiprostone: evaluation report. 2014. http://www.nice.org.uk/guidance/ta318/ resources/constipation-chronic-idiopathic-lubiprostoneevaluation-report. Accessed 05 May 2017.

33. Sucampo Pharma Europe L. Final Study Report-SPL$0211 \mathrm{CC} 0832$.

34. Guest JF, Clegg JP, Helter MT. Cost-effectiveness of macrogol 4000 compared to lactulose in the treatment of chronic functional constipation in the UK. Curr Med Res Opin. 2008;24(7):1841-52. https://doi.org/10.1185/03007990802102349.

35. National Health Service. Department of Health Reference Costs 2015-16. 2016. https://www.gov.uk/government/publications/ nhs-reference-costs-2015-to-2016. Accessed 20 Oct 2017.
36. Curtis L. Unit Costs of Health and Social Care 2016. In: Personal Social Services Research Unit. Personal Social Services Research Unit, Canterbury, University of Kent. 2016. http://www.pssru.ac. uk/project-pages/unit-costs/unit-costs-2016/ Accessed 20 Oct 2017.

37. National Institute for Health and Care Excellence (NICE). Lubiprostone for treating chronic idiopathic constipation: Technology Appraisal Guidance [TA318]. 2014. https://www.nice. org.uk/guidance/ta318. Accessed 16 Mar 2017.

38. Nelson A, Camilleri M, Chirapongsathorn S, Vijayvargiya P, Valentin N, Shin A, et al. Comparison of efficacy of pharmacological treatments for chronic idiopathic constipation: a systematic review and network meta-analysis. Gut. 2016. https://doi.org/ 10.1136/gutjnl-2016-311835.

39. Nuijten M, Bubois D, Joseph A, Annemans L. Cost-effectiveness of prucalopride in the treatmnet of chronic constipation in the Netherlands. Front Pharmacol. 2015. https://doi.org/10.3389/ fphar.2015.00067.

40. Huang H, Taylor D, Carson R, Sarocco R, Friedman M, Munsell $\mathrm{M}$, et al. Economic evaluation of linaclotide for the treatment of adult patients with chronic idiopathic constipation in the US. Manag Care. 2016;25(2):41-8.

41. Taylor RR, Guest JF. The cost-effectiveness of macrogol 3350 compared to lactulose in the treatment of adults suffering from chronic constipation in the UK. Aliment Pharmacol Ther. 2010;31:302-12.

42. Eddy D, Hollingworth W, Caro JJ, Tsevat J, McDonald KM. JB. W. Model transparency and validation: a report of the ISPORSMDM modelling good research practices task force-7. Value Health. 2012;15:843-50.

43. National Institute for Health and Care Excellence (NICE). Costing Template: Prucalopride for the treatment of chronic constipation in women. 2010. https://www.nice.org.uk/guidance/ ta211/resources. Accessed 16 Aug 2017. 